MIDPI

MOL2NET, International Conference Series on Multidisciplinary Sciences http://sciforum.net/conference/mol2net-03

sciforum

\title{
Computational Study (In Silico) of the Antimicrobial and Toxicological Potential of Isoeugenol
}

Sávio Benvindo Ferreira (E-mail: saviobenvindo@ gmail.com) a, Tassiana Barbosa Dantas (E-mail: tassianadantas@ hotmail.com) ${ }^{\text {a }}$, Daniele de Figuerêdo Silva (E-mail: danielefigueredo31@ gmail.com) ${ }^{\text {a }}$, Edeltrudes de Oliveira Lima (E-mail: edelolima@yahoo.com.br) ${ }^{\mathrm{a}}$.

${ }^{a}$ Postgraduate Program in Natural and Synthetic Bioactive Products, Federal University of Paraíba, João Pessoa - PB.

\section{Graphical Abstract}
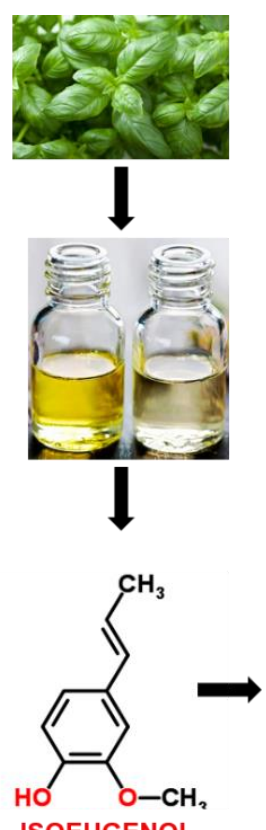

ISOEUGENOL
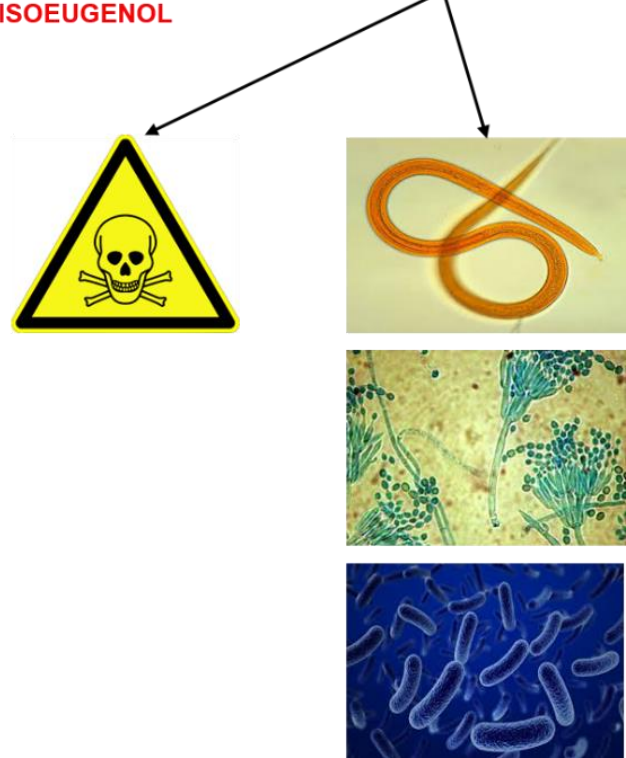

\section{Abstract.}

The search for new compounds with antifungal activity has become very important, mainly due to the large increase of fungal infections and also the appearance of antifungal resistant strains available in the market, as well as for use for pest control. Medicinal plants represent an alternative for the substitution of these synthetic fungicides for natural products, since they have a large quantity and variety of secondary metabolites with biological properties, among them, phenylpropanoids. Therefore, the present study aims to investigate the in silico antimicrobial and toxicological potential of 2-Methoxy-4propenylphenol (isoeugenol) through computational analysis. For this, the Prediction of Activity Spectra for Substances (PASS online), Molinspiration and Osiris software were used. PASS online showed that isoeugenol has the opportunity to present antiseptic (Pa: 0.571 and Pi: 0.009), antifungal (Pa: 0.492 and Pi: 0.032), antibacterial (Pa: 0.379 and $\mathrm{Pi}: 0.035)$, antimycobacterial (Pa: and $\mathrm{Pi}: 0.022$ ) and antihelmintic (Pa: 0.335 and $\mathrm{Pi}$ : 0.028), mainly against nematoda (Pi: 0.562 and $\mathrm{Pa}$ : 0.009). Molinspiration showed that the phytoconstituent has good potential for oral bioavailability, with $\mathrm{nDLH}=1, \mathrm{nALH}=2$, mass $=164.2 \mathrm{Da}$ and 
cLogP $=2.38$. In the analysis with the Osiris program, it was demonstrated that isoeugenol has low irritant (1) and tumorigenic risk (1), and high mutagenic risk and high reproductive toxicity. In view of this instilled study, it was possible to verify that the compound is a potential candidate for in vitro and in vivo studies of antimicrobial and toxicological action and to prove the data obtained from the computational analysis.

\section{Introduction}

The occurrence of antifungal resistance cases used in clinical practice has made the search for new molecules with potential biological activity increasingly subject to studies related to antimicrobial activity [1-2]. Thus, the search for new substances capable of combating fungal infections, or even improving the action of antifungal agents commonly used in the clinic, may be a promising path to fight against resistance and reduce the limitations of conventional treatment, such as adverse effects and high toxicity [3], not only in human use, but also in pest control in agriculture.

Alternatively, we have plants as sources of new biologically active compounds. The great quantity and diversity of secondary plant metabolites has been attracting the interest of researchers from different areas of science, who see in plants a promising source for the discovery of molecules with potential human use, with significant commercial value in the pharmaceutical, food, agronomic and cosmetic [4]. These studies are important for the discovery of compounds with biological activities, since their structural diversity of these substances is greater than that presented by most of the combinatorial strategies carried out on heterocyclic compounds [5]. These characteristics give these compounds a greater possibility of becoming tools in the fight against diseases, among them microbial infections.

To help in this search for new molecules, medical chemistry emerges as a major tool. The aim of medical chemistry is the planning, discovery, identification, preparation and understanding of the molecular action functioning of biologically active compounds [6]. Medical chemistry also takes into account metabolism, chemical structure and pharmacological activity [7].

The use of computational tools brought more speed and efficiency in the development of new drugs. The in silico drug discovery process involves the identification of the target of interest (receptor structure), the choice of compounds from inhibitor bases, evaluation of protein interaction with possible inhibitors, and calculation of pharmacokinetic and pharmacodynamic properties of possible inhibitors [6].

Given this perspective and knowing that the antifungal activity of natural compounds has been scientifically attributed to essential oils, extracts, coumarins, terpenes, flavonoids, amides, alkaloids and even phenylpropanoids [8-11], the aim of this study was to investigate the in silico antimicrobial and toxicological potential of 2-Methoxy-4-propenylphenol (isoeugenol) phenylpropanoide by means of computational analysis.

\section{Materials and Methods (optional)}

The computational analyzes of the antimicrobial activities and toxicological risk of isoeugenol were carried out using the online PASS software, Molinspiration Molecule Viewer and Osíris. 
The "Prediction of Activity Spectra for Substances" - PASS online is software designed to evaluate the overall biological potential of an organic molecule on the human organism, according to its structural arrangement. The spectrum of biological activities of a chemical compound is the set of different types of biological activities, which reflect the results of interaction of the compound with various biological entities. In this way, the online PASS provides several facets of the biological action of a compound, obtaining the indexes $\mathrm{Pa}$ (probability of being active) and Pi (probability of being inactive) by estimating the categorization of a potential compound to belong to the subclass of active or inactive compounds, respectively [12].

The Molinspiration Molecule Viewer software allows the perception of molecules using sophisticated Bayesian statistics, which combine the structures and properties of the representative active compound in the specific target with the structures of inactive molecules, to recognize typical substructure characteristics of the active molecules. This program is capable of evaluating the molecule providing several parameters, among them the ability to predict the probability of the compound to act on certain pharmacological targets [13-14].

To verify the toxicity and theoretical pharmacokinetic parameters of isoeugenol, the compound was subjected to the in silico study of ADMET parameters (absorption, distribution, metabolism, excretion and toxicity) using the Osiris program. This online tool is able to predict the toxicity of the substance by comparing its chemical structure with molecular fragments whose defined toxicity is found in a database. The toxicity results are expressed as mutagenic, tumorigenic, irritability and effects on the reproductive system [15].

After analysis, the software provided the potential of druglikeness and drug-score that are related to topological descriptors, and other properties such as cLogP and molecular mass, in addition to theoretical analysis of mutagenic, tumorigenic, irritant and reproduction effects. The results obtained were then classified from a scale of 1 to 3, where: 1 means absence of toxicity, 2 moderate toxicity and 3 severe toxicity. In addition to reporting the possible toxicity of a molecule, Osiris is able to report important physicochemical parameters in predicting the theoretical oral bioavailability of the drug under study. These parameters are: partition coefficient (water / oil) - cLogP, molecular weight, number of hydrogen acceptors - nALH, number of hydrogen donors - nDLH [15].

To verify whether the compound can be planned for oral administration, an analysis based on the "Rule of Five" was performed, as described by Lipinski [16]. In this rule, if the molecule shows scores of at least 3 parameters meeting the requirements $(\operatorname{cog} \mathrm{P} \leq 5$, molecular weight $<500$ daltons; $\mathrm{nALH} \leq$ $10 ; \mathrm{nDLH} \leq 5$ ), the molecule will theoretically present a good oral bioavailability.

\section{Results and Discussion (optional)}

After analysis of the probable biological activities of isoeugenol through the online PASS, more than 522 activities with more than $30 \%$ of the probability of being active ( $\mathrm{Pa}>30 \%$ ) were obtained, of this total, 49 activities have a high probability of occurrence $>70 \%$ ). The computational study revealed the activities most likely to be exerted by the compound. Among the 522 activities with a chance of being performed by isoeugenol, we highlight the antimicrobials: antiseptic (Pa: 0.571 and Pi: 0.009), antifungal (Pa: 0.492 and Pi: 0.032), antibacterial (Pa: 0.379 and Pi: 0.035), antimycobacterial (Pa: 0.478 and Pi: 0.022) and antihelmintic (Pa: 0.335 and Pi: 0.028), mainly against nematoda (Pi: 0.562 and $\mathrm{Pa:}$ 0.009).

These antimicrobial activities can be attributed to several characteristics of isoeugenol reported in the literature. Bhatia et al. [17] found that the antifungal activity of isoeugenol against strains of 
Candida spp. is due to the ability to inhibit $\mathrm{H}+$ pumping through plasma membrane ATPase and alteration of fungal membrane permeability. These data are supported by the results of the online PASS analysis, which demonstrates that the phytoconstituent has a considerable chance of exerting instability in the fungal plasma membrane as a membrane permeability potencilizer (Pa: 0,408 and $\mathrm{Pi}: 0,054)$ and membrane integrity antagonist (Pa: 0.316 and Pi: 0.105). These data support the hypothesis advocated by Sikemma et al. [18] and Gill et al. [19] that attribute to isoeugenol the destabilizing action of the fungal membrane due to its chemical structure.

Next, the molecular properties of isoeugenol, based on molecular descriptors using Lipinski's rule of five, were calculated in the Molinspiration Online Property Calculation Toolkit software (Table 1). Lipinski's rule of five establishes some structural parameters relevant to the theoretical prediction of the oral bioavailability profile, which is added to the absorption and permeability of possible drugs and depends on five parameters: (1) number of hydrogen bonding groups (nALH ) less than or equal to 10; (2) number of donor hydrogen bonding groups (nDLH) less than or equal to 5; (3) molecular mass (MM) less than or equal to $500 \mathrm{~g} / \mathrm{mol}$; (4) octanol-water partition coefficient (milog P) less than or equal to 5; (5) polar surface area (PSA) less than or equal to $140 \AA$ A. Molecules that violate more than one of these rules may have problems with bioavailability.

Table 1 - The theoretical analysis of the physico-chemical properties of isoeugenol required for theoretical oral bioavailability compared to the standard of the Lipinski's rule of five - Osiris

\section{Parameters for Bioavailability Evaluation}

\begin{tabular}{ccccc}
\cline { 2 - 4 } Phytoconstituent & nDLH & nALH & Da & cLogP \\
\hline \multicolumn{1}{c}{ Isoeugenol } & 1 & 2 & 164.20 & 2.38 \\
$\begin{array}{l}\text { Padrão da "Regra dos } \\
\text { cinco" Lipinski }\end{array}$ & $=5$ & $=10$ & $<500$ & $<5$ \\
$\begin{array}{l}\text { nDLH: Number of hydrogen donors; nALH: Number of hydrogen acceptors; Da: Molecular weight; cLogP: } \\
\text { Partition coefficient water: oil. }\end{array}$
\end{tabular}

Analyzing the results obtained in Osiris through Lipinski's "Rule of Five" [16], it was verified that isoeugenol presents a good theoretical oral bioavailability, since all the physicochemical parameters evaluated for this molecule presented within the cut established by the "Rule of Five" Lipinski.

The study of drug likeness and drug score was performed using the Osiris Property Explorer program (Table 2). Drugcore values between 0.1 and 1.0 and a positive value for drug likeness indicate that the molecule evaluated contains frequent groups in commercial drugs. The theoretical toxic effects evaluated were mutagenicity, tumorogenicity, irritant effects and human reproduction through color (red $=$ high risk, yellow $=$ moderate risk and green $=$ no risk $)$.

Table 2. Risk of toxicity of isoeugenol compared to standard antifungal (voriconazole) calculated using Osiris Property Explorer software.

\begin{tabular}{|l|c|c|c|c|}
\hline \multirow{2}{*}{ Compounds } & \multicolumn{4}{|c|}{ Toxicity risk } \\
\cline { 2 - 5 } & MUT & TUMO & IRRI & REP \\
\hline
\end{tabular}




\begin{tabular}{|l|l|l|l|l|}
\hline Isoeugenol & & & & \\
\hline Voriconazole & & & & \\
\hline
\end{tabular}

: Nontoxic; Reproductive effective.

According to the in silico toxicity analysis of the compound, it has been found that it does not present a risk of being irritant and tumorigenic. Although it has demonstrated a high risk of being mutagenic and presenting reproductive toxic effects, these data do not exclude it from being a drug candidate, since other antimicrobial drugs, such as itraconazole, also present a high tumorigenic and mutagenic risk [20].

\section{Conclusions}

The in silico study identified the antimicrobial potential of isoeugenol, as was expected according to the literature, and identified the phytoconstituent toxic profile likely to be developed by the compound when in contact with the organism. Thus, this preliminary computational analysis allows us to continue the studies of isoeugenol in other experimental models.

\section{References (mandatory)}

1. Ahmad, A. et al. Evolution of ergosterol biosynthesis inhibitors as fungicidal against Candida. Microbial Pathogenesis, v. 48, p. 35-41, 2010.

2. Duarte, M.C. et al. Anti-Candida activity of brazilian medicinal plants. Journal of Ethnopharmacology, v. 97, p. 305-311, 2005.

3. Zuzarte, M. et al. Antifungal activity of phenolicrich Lavandula multifida L. essential oil. European Journal of Clinical Microbiology \& Infectious Diseases, v. 31, p. 1359-1366, 2012.

4. Simões, C. M. O.; Spitzer, V. Óleos voláteis. In: Farmacognosia da planta ao medicamento; Editora da UFRGS, Porto Alegre; Florianópolis, p. 379-380, 2007.

5. Harvey, A. The pharmacology of galanthamine and its analogues. Pharmacol Ther 68: 113-128, 1995.

6. Zoete, V., Grosdidier, A., Michielin, O. Docking, virtual high throughput screening and in silico fragment-based drug design. Journal of Cellular and Molecular Medicine. v.13, n. 2, p. 238-248, 2009.

7. Wermuth, C. G. The practice of medicinal chemistry. London: Academic Press. 2003.

8. Aquino, P.L.P., Lima, E.O., Farias, M.P., Freire, K.R.L., Souza, E.L., Cechinel Filho, V., Corrêa, R., Andricopulo, A. Atividade antifúngica de maleimidas contra dermatófitos isolados de Tinea captis. Revista Brasileira de Análises Clínicas, v, 35, n. 4, p.191-194, 2003.

9. Gayoso, C. W., Lima, E. O., Oliveira, V. T., Pereira, F. O., Souza, E. L., Lima, I. O., Navarro, D. F. Sensitivity of fungi isolated from onychomycosis to Eugenia cariophyllata essential oil and eugenol. Fitoterapia, v. 76, n, 2, p.247-249, 2005.

10. Moreira, A. C. P., Lima, E. O., Souza, E. L. et al. Inhibitory effect of Cinnamomum zeylanicum Blume (Lauraceae) essential Oil and beta-pinene on the growth of dematiaceous moulds. Braz $\mathbf{J}$ Microbiol 2007; 38:33-38.

11. Oliveira, L. B. S., Batista, A. H. M., Fernandes, F. C., Sales, G. W. P., Nogueira, N. A. P. Atividade antifúngica e possível mecanismo de ação do óleo essencial de folhas de Ocimum gratissimum (Linn.) sobre espécies de Candida. Rev. bras. plantas med., Botucatu, v. 18, n. 2, p. 511-523, June 2016. 
12. Srinivas, N., Sandeep, K. S., Anusha, Y., Devendra, B. N. In Vitro Cytotoxic Evaluation and Detoxification of Monocrotaline (Mct) Alkaloid: An In Silico Approach. Int. Inv. J. Biochem. Bioinform, 2(3):20-29, 2014.

13. Ertl, P., Rohde, B., Selzer, P. Fast calculation of molecular polar surface area (PSA) as a sum on fragment-based contributions and its application to the prediction of drug transport properties. Journal of Medicinal Chemistry, v.43, n.1, p.3714-3717, 2000.

14. Gupta, A., Aniyery, R. B., Pathak, A. In silico pharmacological and in vitro biological study of novel organotinsorbate. Int J Pharm Sci Res, 8(10): 4201-4212, 2017.

15. Ursu, O., Rayan, A., Goldblum, A., Oprea T. Understanding drug-likeness. WIREs Comput. Mol. Sci, 1, 760-781, 2011.

16. Lipinski, C. A., Lombardo, F., Dominy, B. W., Feeney, P. J. Experimental and computational approaches to estimate solubility and permeability in drug discovery and development settings. Adv Drug Deliv Rev 46:3-26, 2001.

17. Bhatia, R., Shreaz, S., Khan, N., Muralidhar, S., Basir, S. F., et al. Proton pumping ATPase mediated fungicidal activity of two essential oil components. J Basic Microbiol 51: 1-9, 2011.

18. Sikemma, J., De Bont, J., Poolman, B. Mechanisms of membrane toxicity of hydrocarbons. Microbiol. Rev, 59, 201-222, 1995.

19. Gill, A., Holley, R. Disruption of Escherichia coli, Listeria monocytogenes and Lactobacillus sakei cellular membranes by plant oil aromatics. Int. J. Food Microbiol, 108, 1-9, 2006.

20. Silva, D. F., Medeiros, C. I. S., Oliveira Filho, A. A. Avaliação in silico do risco de toxicidade do $\beta$ - citronelol. Congresso Brasileiro de Ciências da Saúde, Campina Grande - PB, 2016. 